\title{
The development and research of 3D Anthropometric Database \\ Management System
}

\author{
Lei Xia ${ }^{1, \text { a }}$, Wan Zhen ${ }^{2}$ \\ ${ }^{12}$ College of Fashion Technology, Shanghai University of Engineering Science, Shanghai 200065, P. \\ R. China, \\ a shirleygreen168@163.com
}

\begin{abstract}
Key words: 3D body measurement, Database, Database Management System, ASP.NET, VB.NET, SQL Server, B / S

Abstract. This paper researched the application of the framework, mechanism of inheritance, complex objects and the data storage technology, establishing a good management mechanism for updating data constantly, and completing development of this three-dimensional human data management system. By measuring 1,800 children aged $4-16$ years old in Shanghai Song jiang and the surrounding areas, we collected the corresponding data. Microsoft ASP.NET was used in this system as programming framework, basing on the common language of VB.NET, 64 digital high-end database software - SQL Server 2000 which is Microsoft Corporation developed as a background support was used, and sql.server.net was used as main data link.
\end{abstract}

\section{Introduction}

With the development of the times, people' Requirements for clothing is no longer confined to cover their body and keep warm. Requirements for comfort and fitness are the people's goals. Human data lagging behind comfort and fitness research becomes a big obstacle. The task used B / S system as the realization technology of system framework, which greatly simplifies the client. As long as the client machines access to the Internet can be achieved, WAN data synchronization update, the costs of system update and maintenance are low, a seamless system upgrade can achieve. By using Photoshop transparent texture icon technique, the task completes system icon design and brings forward E-Human concept. The 3D human data management system has good expandability, and maintainability. The system function include such as remote inquiry, administrator server management, basic statistical functions, Excel statements upload and download functions.

\section{Experimental Sample and method}

This survey samples came from 1800 boys and girls vary from 4 to 16 years old. 1800 samples for measurement were chosen in Songjiang area of ShangHai with the way of cluster sampling.

All samples were measured by non-contact 3D body scanning system; they were naked, keeping a natural upright posture with even breath during the measurement [1]. Three postures were adopt, the first position is feet apart and keeping shoulder width, arms straight, five fingers and thigh maintain a fist distance, the second position is sitting on a chair adjusted to the high position, upper body natural straight, the left leg parallel to the right leg, the knees being bent into $90^{\circ}$, two feet flatting on the ground, right arm extension, left arm keeping upper arm perpendicular to small arms, and keeping head straight. The postures are shown in Fig 1. 

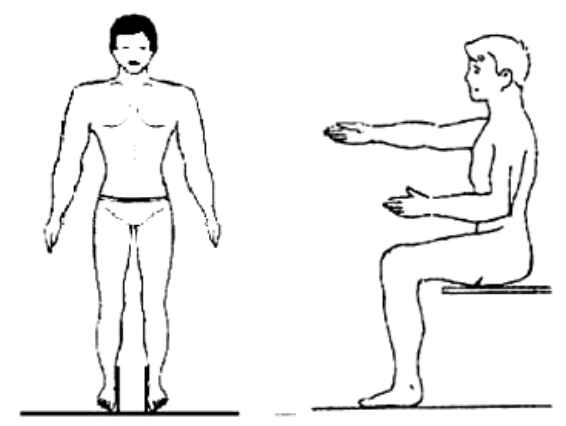

Fig 1 Three postures of 3D body scanning

The experiment lasted more than a month, and the data keep accuracy and completeness throughout the entire process. Its purpose is to ensure the data integrity and credibility in the three-dimensional human data management system [2].

There were total 30 measurement items being taken into this survey: height, weight, head circumference, bust circumference, under the bust, neck circumference, waist circumference, hip circumference, arm circumference, upper arm circumference, middle arm circumference, wrist circumference, palm circumference, maximum thigh circumference, maximum circumference of calf, foot circumference, shoulder length, across back, chest width, full arm length, arm length, upper arm length, front length, back length, thigh length, foot length, cervical point height, sitting position of cervical vertebra, waist height, Knee high.

\section{Preprocessing of human body size data}

Establishment and editing of human dimension data. According to the data file and manual measurement of 3D human body scanner, all human body size data is entered, and the special data file format is adopted to search and summarize the documents. Edit and check each data file, and its contents include:

1. In the document, the entry of the project or the deletion or deletion of the item is deleted or re processed.

2. Additional input to the individual sample data for the entry.

Detection and preprocessing of abnormal data of human body size. In mass survey, the measurement, recording and recording of all the technical aspects of the human body data will inevitably be wrong, so data processing must be checked before and processing abnormal data [3]. This study reviewed all of the human body size data in the following method, and the abnormal data were processed scientifically.

1.Calculate the mean and standard deviation of the measurement items and the data standardization.

2. Find unreasonable abnormal data source of error, flipping through the original records, in the case of input error is modified and, in the case of a possible special body is retained, if can correct the error is only in respect of the project excluding.

3. Repeat step 1 and step 2, until the error is modified.

\section{Design and establishment of 3D human data management system}

The main functions of this system include: the function of adding, deleting, modifying, and having the function of basic statistical analysis, it can provide a more comprehensive control to the individual. It is suitable for each department personnel and business unit to have the right to use the system to carry on the basic query, statistical analysis and so on. 


\section{The main function of the system}

\section{Data collection and input}

It builded a general model of the shared information database, and provided convenient and practical information storage and access tools to all users.

2. Data transmission and verification

It could transfer the data collected from the distributed front end station, carry on the test to the data, and store the data to the shared database.

3. Data query

Data query function can be based on user needs to enter the ID number to find the fuzzy search, and its paging.

4. Data analysis

It could do basic statistical calculation of the human body size data, including the calculation of the minimum, maximum, arithmetic mean, variance, standard deviation, etc.

5. System management

It contained the user and the use of authority management, system initialization (first put into use when the completion of the system initialization work), and provide data import and export, regular backup, recovery and fixed recovery and other functions.

Establishment of database. Server SQL 2000 is a scalable relational database based on Structured Query Language (SQL), which supports extensible markup language (XML) for Internet applications, and consists of a database, relational database, structured query language and extensible markup language. Based on the above characteristics, Server SQL 2000 was used as the database development language.

Determine the table in the database. In order to achieve resource sharing, control the user's authority, carry out data and statistical analysis easily; we can design several data tables: urban information table, user information table, permission application form (such as table 1), and children's body measurement data Table 1 .

Table 1 Permission application form

\begin{tabular}{|l|l|l|l|l|}
\hline Field name & Data type & Field size & main code & $\begin{array}{l}\text { Outercode } \\
\text { connection }\end{array}$ \\
\hline Id & int & 4 & YES & \\
\hline UID & varchar & 50 & NO & \\
\hline data table & varchar & 50 & NO & \\
\hline reason & nvarchar & 50 & NO & \\
\hline phone & int & 4 & NO & \\
\hline mobile & int & 4 & NO & \\
\hline email & varchar & 50 & NO & \\
\hline
\end{tabular}

Programming. Through using.Net technology, we selected and established the Web VB.NET applications. Each page was achieved through the preparation of the front page .Aspx, background process. Aspx.vb, and automatically generate .Asax file. The successful operation of each page was built on the basis of the three documents.

The realization technology of the system structure. In this paper, we choose the B/S module; use ASP.NET to develop with good scalability and maintainability. The user remote query, the Administrator Server management, basic statistical functions, Excel report upload and download and other functions were realized.

Realization technology of inheritance mechanism. Inheritance is a kind of relationship between class and class. Definition: "class B inheritance class A", or "A derived class B". The grammar of inheritance: 
Class derived class: class base \{

Public: public member list;

Protected: protected member description list;

Private: private member description list;

;

Inheritance access control rule is listed in Table 2:

Table 2 Inheritance access control rule

\begin{tabular}{|l|l|l|}
\hline $\begin{array}{l}\text { Inheritance access } \\
\text { control rule }\end{array}$ & $\begin{array}{l}\text { Base class member access } \\
\text { control }\end{array}$ & Access control in derived classes \\
\hline \multirow{4}{*}{ public } & public & public \\
\cline { 2 - 3 } & protected & protected \\
\cline { 2 - 3 } & private & Not accessible \\
\hline \multirow{3}{*}{ protected } & public & protected \\
\cline { 2 - 3 } & protected & protected \\
\cline { 2 - 3 } & private & private accessible \\
\hline \multirow{3}{*}{ private } & public & private \\
\cline { 2 - 3 } & protected & Not accessible \\
\cline { 2 - 3 } & private &
\end{tabular}

\section{Results and Discussions}

Along with the development of clothing production technology, people's pursuit of clothing is not just a cover body warm function, fitness, comfort has become the main indicator of people choose clothes. At present, the human data update is lagging behind, so it is urgent to research and develop a 3D human data management system which is based on the new generation network technology. This research mainly includes several aspects:

Data of 1800 children were measured by the 3D human body scanner, and the database platform of male and female was provided in the system.

In this paper, some key technologies of SQL Server.NET are studied. With computer and network technology, through the design of the front page and the preparation of the background process, the database and real-time data exchange were completed. Landing system, database data and other relevant pages were all used the dynamic pages writing technology.

Through the research of the system architecture, inheritance mechanism, and complex objects, the security of the system were greatly enhanced, and the probability of data theft was reduced.

\section{References}

[1] Danielle L. Esme, Alexander Bucksch, Werner H. Beekman.Three-Dimensional Laser Imaging as a Valuable Tool for Specifying Changes in Breast Shape After Augmentation Mammaplasty. Aesth Plast Surg (2009) 33:191-195.

[2] Becker S, Haala N (2007) Combined feature extraction for façade reconstruction. ISPRS workshop on Laser Scanning and Silvi-Laser 2007, Espoo, Finland. 
[3] Bucksch A, Lindenbergh R, Ree J (2007) Influence of the intensity remission on the scan quality. In: Presented at the symposium on the error budget of terrestrial laserscanning, GeoSiberia, Novosibirsk, Russia. 